\title{
Innocent and Innocuous: The Case Against Animal Research*
}

\author{
Joel Marks \\ Professor Emeritus of Philosophy \\ University of New Haven \\ and \\ Bioethics Center Scholar \\ Yale University \\ JMarks@newhaven.edu
}

\begin{abstract}
Animal research is a challenging issue for the animal advocate because of what, besides animal well-being, is considered to be at stake, namely, human health. This article seeks to vindicate the antivivisectionist position. The standard defense of animal research as promoting the overwhelming good of human health is refuted on both factual and logical, or normative-theoretical, grounds. The author then attempts to clinch the case by arguing that animal research violates a deontic principle. However, this principle falls to counterexample. The author concludes, nevertheless, that the principle retains force as a presumption that the current state of affairs fails to overthrow. This does suggest, though, that the antivivisection movement would be well advised to keep ahead of the curve. The author proposes it do so by emulating the vegan movement against animal agriculture with the active promotion of alternatives to animal research.
\end{abstract}

\section{Introduction}

Some people, such as myself, have a strong intuition that animal research is wrong. By "animal research" I refer to the use of nonhuman animals in laboratory experimentation that involves, typically, causing them distress, pain, or mutilation, housing them in cages, and, finally, killing them. Put this way, it may seem surprising that it should be difficult to prove the soundness of the intuition. But animal research is an exceptionally challenging issue for animal advocates, and for two reasons.

First is that the number of animals used in laboratories, while in the millions, is still vanishingly small compared, say, to how many are raised and slaughtered for human food. As another article puts it:

"From a statistician's point of view ... all animals [with whom humans interact in the United States] are farmed animals; the number that 
are not is statistically insignificant" (Wolfson and Sullivan 2004, 206).$^{1}$ Why then make an issue of animal research, especially if one is concerned about animals? Shouldn't the animal movement focus its attention and resources where they could do the most good?

The second cause for pause is that opposition to animal research, particularly of the medical variety, seems to be up against matters of life and death for human beings. The use of animals for food is much easier to attack because human beings do not need to eat animals in order to survive or even to thrive. ${ }^{2}$ But that animal research has made the difference between sickness and health, debility and capability, pain and relief, untimely demise and longevity, including for other animals who are treated by veterinarians, seems beyond question. As a prominent animal-rights proponent has put it, "The argument that it is necessary to use nonhumans in biomedical research, though flawed, is at least plausible, unlike our necessity arguments for other animal uses" (Francione 2007, 241).

Against this formidable challenge, and indeed precisely because of it, understanding what is wrong with animal research could be the key to understanding what is wrong with the use of animals in general. For if it can be convincingly demonstrated that even a minimal number of animals ought not to be used even when human existence would be significantly benefited thereby, as in medical experimentation and toxicological testing, then the case will surely have been made for also refraining from all of their other, more widespread yet trivial uses, such as palate-pleasing, clothing, sport, and entertainment. In this essay I will therefore undertake to refute the best argument the research defender has to offer, and also propose my own argument against animal research. Alas, my efforts will meet with only tentative theoretical success; but that will be sufficient to suggest a compensating practical program of animal advocacy. 


\section{The Best Defense of Animal Research, and Its Refutation}

The best defense of animal research is that it promotes the welfare of humanity. But this very defense would seem to present a moral paradox. For presumably other animals are used in this work because of their similarities to human beings: how else to obtain results that are relevant to our primary concern with human health? On the other hand, this use of animals fails to accord them any moral status even approaching our own. But if other animals are so similar to us, then why don't they deserve similar moral consideration? ${ }^{3}$

The defender of animal research claims to be able to defang this objection. To begin with, she maintains, the animals do receive due consideration. In recent years animals in labs have increasingly been accorded humane treatment. But, I reply, there remain gaping loopholes. The most obvious is that the only federal legislation protecting animals in laboratories (in America), the Animal Welfare Act, explicitly excludes upwards of 90 percent of those animals by the simple expedient of excluding rodents, among others, from the definition of "animal" (Plous 1999). But even though other guidelines and protections are in place, the main problem is with the very meaning of "humane" and related terminology. In animal research one enters an Orwellian world where cruelty is humane, exploitation is sacrifice, and killing is welfare, or so I will argue below in the section on rhetoric.

A second and more forceful rebuttal by the research defender, however, is that, humane or inhumane, and animal/human similarities notwithstanding, animal research is justified by the greater good it generates. By sacrificing a relatively small number of animals now, medical science lays the groundwork for alleviating pain, impairment, and premature death for untold millions of human beings into the indefinite future. This is surely the central argument in support of animal research. But it can be refuted, and by both of the standard, rational ways of doing so, namely, denying the truth of the premise and the validity of the inference. 
The premise of the argument is that animal research has a significant payoff in alleviating human misery. But this claim has been challenged by a number of researchers on empirical grounds; the evidence may be simply lacking (Pound et al. 2004). Yet even if it were shown that animal research has in fact led to the claimed result, it would not follow logically that the research is justified. There are two distinct reasons for saying this. Both are based on the utilitarian presumption of the argument supporting animal research.

Utilitarianism is the moral thesis that the end justifies the means. Thus, the argument we are now criticizing has claimed, in effect, that the end of human welfare justifies the use of nonhuman animals in the laboratory as means to that end, even if the welfare of those animals is compromised in the process. And, we are now granting for the sake of argument, human welfare has been furthered in just this way.

The first objection to this argumentative employment of utilitarianism is that it distorts the meaning of utilitarianism. For utilitarianism does not mandate that any practice that produces some good, even significant good, is justified, but only that a practice that produces the most good (or the least bad) should be done. After all, if we were using our national health budget to alleviate the suffering of one million people, that would be a good; but if we could alleviate the same suffering of ten million people by using alternative strategies but the identical budget, then, all other things equal, that change would not only be better, but, it seems plausible to maintain, obligatory.

So the real question in the present case is: Has animal research shown itself to be more effective than any alternative sort of research that might have been done all these years in its stead? And even if it has, the more relevant question to the present day is to ask: Is there good reason to believe that continuing to invest in the animal infrastructure of research would be more conducive to medical progress from here on than would investing equivalent resources in any alternative methodologies? The answers to these questions are 
far from obvious, and indeed a compelling case can be made that the answer to both is No (Bass Forthcoming). Consider, for example, that a medical science that is premised on animal research contains, as "costs," both false negatives, such as drugs that proved harmless in other animals but turned out to be harmful to humans, and false positives, such as potentially useful drugs for humans that were never developed because they proved harmful to other animals. It has even been suggested that medical research itself should perhaps be demoted, since enough is already known to justify shifting major resources to the promotion of exercise, relaxation, and proper diet as the most effective means to the end of public health. ${ }^{4}$

It would be very odd, by the way, were the research proponent to argue that a rigorous demonstration of the superior efficacy of using animals is not required since it is "obvious." For science itself is built on the premise that one cannot trust in the obvious. And why else would those who do basic animal research in particular be devoting countless hours (and "sacrificing" countless animals) to ascertain such things as whether other animals are conscious, rational, and sentient, and can experience pain, suffering, and joy, all of which are obvious? ${ }^{5}$

The second objection to the utilitarian argument for animal research is that it employs utilitarianism in bad faith. For if medical researchers were truly utilitarian, would they not be using human beings for much of the research for which they currently use other animals? After all, however similar other animals may be to human beings, human beings are even more similar because they are identical. So clearly human beings would serve as superior models of human disease, etc. But of course we would never use them in this way. More precisely, since some researchers have in fact done just that, for example, in Nazi concentration camps and in the Tuskegee syphilis experiment, such use is today universally deplored.

If one grants that the utilitarian basis for animal research has thus been discredited, then one is left with no moral defense of 
animal research at all, or else only the cynical one that, as theologian Andrew Linzey is wont to put it (while of course rejecting it), "might is right" (Linzey 2009). The contradiction of our use of these animals is left in place, and we use them simply because we can. Human beings have achieved almost absolute power over all of the other species of the Earth ${ }^{6}$ and have exercised that power willy-nilly. The fact that the medical use of them happens to be the most compelling use does not change the fact that we have implicitly performed a kind of reversal of a common principle of ethics. For it is generally agreed that "ought" implies "can"; that is, we have no obligation to do anything that we are incapable of doing. But animal research inverts this to "can" implies "ought" (or at least "permissible") - a pseudoprinciple we would never think to apply in other contexts. Just because you might be capable of murdering a forest recluse and getting away with it does not mean that you are morally entitled to do it, not even if you could thereby steal enough money to support your starving family. So why is it OK to do the equivalent to a rat in a lab in a speculative effort to find a cure for your child's cancer?

\section{One More Go-around}

There is a more direct defense of animal research, which some are willing to offer unabashedly even though others denigrate it as "speciesism," that goes like this. Even absent compelling proof that animal research is effective or the most effective way to promote human health with our research dollars, we are justified to engage in it, absent a clear alternative path, simply because we value other animals much less than we value human beings. In this sense the "moral cost" of using animals in the lab is easily outweighed by even the tenuous hope of advancing human interests.

I reply to this in two ways. First I question the premise. For while it is certainly true that human beings commonly behave as if other animals had very little value, human beings also often behave to the contrary. Pets are the most obvious example, at least if we are talking about the 21st Century United States. It is a commonplace for some 
sort of nonhuman animal to be considered a member of the family in this country (Petside Team, 2009). Furthermore, many, perhaps most of the people who work with animals in laboratories consider themselves to be animal-lovers and are conscientiously concerned to take the best care they can of those animals consistent with the research being undertaken.

So rather than say that human beings de-value other animals, I would say that human beings value them inconsistently. A person who cries over her beloved puppy's wounded paw could also relish eating the leg of a lamb that had been subjected to a cruel life and death. If you have ever entered your child's bedroom in your tenement apartment at night, only to discover a giant rat perched atop him, you might at once commit yourself to the total extinction of the rodent species. But if you have spent many an hour looking into the wise pink eyes of your pet rat, or watching her swinging carefree on a makeshift hammock, or feeling her little paws tickling you as she scurries under your shirt, you might find the thought of her compatriots being dissected and beheaded in laboratories unbearable. What this tells me is that it is simply not true that we do not value other animals highly -- a fortiori, that we are convinced they do not possess such value intrinsically. At "best" it could be said that we allow our feelings towards other animals to be radically skewed by our preferences and by the circumstances.

But this is surely just as true of other human beings, is it not? The most horrific laboratory experiments on other animals are easily paralleled by the atrocities that human beings commit on one another in large numbers. But from this, would it be valid to conclude that human beings do not value human beings, not to mention, that human beings do not possess high value intrinsically? Not at all. Then neither can we conclude that other animals lack high intrinsic worth, and we have much evidence that we do not conclude thus.

Let us suppose, however, that it were true that human beings do not value other animals highly or even that, as a matter of metaphysico-ethical fact, animals have negligible inherent value. This 
brings me to my second criticism of the argument, which is that the conclusion still would not follow. For suppose other animals were intrinsically worthless: their use would still not be "cheap" because of the vast human and technological infrastructure required to conduct research on them. And, reverting to the earlier argument that no clear proof of the superior efficacy of animal research is available, would it not make sense to be redirecting our health-promotion dollars to other practices that have been proven or are likely to be more efficacious? Letting doctors play tiddlywinks all day would not hurt anyone, but we would hardly consider this to be the best use of our healthcare dollars.

\section{Interlude on Rhetoric and Research}

Before I present my argument against animal research, I would like to discuss briefly the use of misleading rhetoric by defenders of animal research. Consider, for example, the term "sacrifice," as in, "The animals are sacrificed for the sake of medical progress." In itself the idea of sacrifice seems noble. Granted also, the notion of "animal sacrifice" is an ancient one. But, just as with the human "sacrifice" of yore, there is something distinctly jarring to the modern ear about "sacrificing" another for one's own gain, and without their consent to boot.

Any nobility of sacrifice would seem to attach to one's doing so voluntarily for the sake of others. In a less noble but still acceptable sense, sacrifice can be made on one's own behalf, as when one forgoes rich desserts in order to lose weight. But to sacrifice another for one's own benefit seems a stretch, indeed a reversal, of the term's legitimate connotations. One would have thought, for example, that the paradigmatic religious image in the West of Jesus's voluntarily replacing the literal lamb of sacrifice on fallen humanity's behalf, as opposed to a literal ram being conscripted to replace Isaac on Abraham's altar, settled this matter in the most conspicuous terms. The animals in the lab are not making a sacrifice. Significant 
numbers of them are being confined, stressed, tortured, mutilated, and killed.

Another term commonly employed by animal researchers is "welfare," and this often in concert with "humane." But, as with "sacrifice," everything depends on how these terms are defined. ${ }^{8}$ For example, a schema dubbed "the five freedoms" has established itself as a touchstone of animal welfare in animal farming (Farm Animal Welfare Council 2009) and has also been applied to laboratory research. ${ }^{9}$ Yet it conveniently omits, for example, the freedom to live out one's natural lifespan. ${ }^{10}$ This schema therefore seems arbitrary from an ethical standpoint and obviously subserving of strictly human interests.

Another example of tendentious narrowing of "welfare" is to deem as "humane" any treatment of the animals that spares them from unnecessary pain, including routinely killing them. But this is doubly disingenuous. First is that pain, by which is usually meant physical pain, is surely only one sort of distress that an animal may undergo in conditions of lifelong confinement and manipulation (Brown 2006). Second is that it relies on a notion of "necessary" that is itself suspect, this being the final example of research rhetoric I will discuss.

Necessity can seem like an absolute notion, but it is actually a relative one; necessity is always for some purpose. (As in the "6os we used to say something was "relevant" ... but relevant to what?) Thus, to say something is "necessary" as such is either to have a hidden agenda or else to try to put something outside the realm of discussion or questioning. (In the latter respect it functions much like the word "sacred.")

In the case just introduced, the "welfare" or "humane" restriction to avoid "unnecessary pain" is meaningless, or at least does not mean what it might appear to mean, because, in this context "necessary" is understood as relative to research. Sometimes this is stated explicitly; 
for example, the following is a suggested guideline for investigating pain in experimental animals: "In studies of acute or chronic pain in animals measures should be taken to provide a reasonable assurance that the animal is exposed to the minimal pain necessary for the purposes of the experiment" (Zimmerman 1983; my emphasis). The practical upshot is that none of the "welfare" guidelines, narrow to begin with, is absolute; and in fact they are frequently honored in the breach, not only illegally but also legally. Therefore, no procedure whatever, no matter how painful, lethal, or cruel, is ruled out by this interpretation of animal welfare and humane treatment.

More generally when researchers speak of the necessity of animal use, what they have in mind, presumably, is human welfare and thriving. So suppose the utilitarian claim were correct that animal research would lead to the best outcome for human beings and, ultimately, the best outcome for all sentient beings in terms of sheer numbers. Then to say that animal research is necessary would be to say that, without it, we could not achieve this desirable result. But what follows from that morally? Would it mean that animal research had thereby been shown to be justified, permissible, indeed, obligatory, in other words, not only not wrong, but "the right thing to do"?

Here is what I find to be the most compelling reason for thinking that the answer is No.

\section{The Moral Argument against Animal Research: A Distinction in Ethics}

I begin my noting that we do countenance the willful harming and even killing of another humanbeing under certain circumstances. Perhaps these can be summed up roughly as: "whenever somebody commits or threatens significant harm to us or to another human being who is herself harmless." I note further that the harm that justifies harm could even be inadvertent, for example, when a SWAT team has to take out the poor guy across the street, who has been deceived by terrorists into believing that the button he is about to 
push will only set off harmless fireworks when in fact it will trigger a huge bomb in the marketplace.

However, I am not aware that we condone the harming or killing of human beings simply in order to avert a bad or bring about a good. Thus, even if the organs from your healthy body could save the lives of five other people, it would never be considered ethical or moral to "farm" you for that purpose. The "missing link" is that, in the normal runs of cases, you are not in any way, either intentionally or unintentionally, responsible for the unfortunate condition of those five other humans. So we draw this ethical distinction: Harming and even killing a human being can sometimes be justified in order to reduce or eliminate something bad, but only in those cases where the victim has been, is, or could plausibly be instrumental (however inadvertently) in causing that bad. ${ }^{11}$

Furthermore, we recognize this distinction with other animals. For example, it is one thing to kill a dog who is rabid, who has harmed or threatens to harm or kill another pet or person. It is quite another thing to kill a non-rabid dog in order to "farm" his organs to save the lives of five other pets. I think we would consider the latter wrong for the same reason as in the human case: There is no universal allowance to harm or kill an animal (human or otherwise) in order to better the lot of others, but only if that animal is somehow instrumental to the harming or killing of those others.

Just so I would argue: It is not enough to note that the "cost" of harming and killing animals in medical research can be "outweighed" by the benefit of promoting human health and welfare, or even that of other animals. It must also be shown that the individual animals being harmed or killed were somehow instrumental to the damage that this research seeks to ameliorate, or are somehow threatening to cause it, however inadvertently. But all lab animals are harmless in these respects: they are both innocent and innocuous. Therefore the burden of proof is on the animal researcher to explain why it is permissible to violate an apparently universal prohibition, in the case 
of animals, ${ }^{12}$ even nonhuman primates,${ }^{13}$ who just happen not to be pets. ${ }^{14}$

But we have seen that the animal researcher has no proof (other than the cynical argument that "might is right"). Therefore etc. Q.E.D.

\section{Conclusion (thus far): Two Rights Do Not Make a Right}

Today's animal researchers believe that their work is justified in two respects, both as to ends and means - a win-win. For their goals are noble -- curing or preventing diseases in humans and other animals and finding ways to relieve suffering and prolong lives - and their methods are humane - making sure that animal use and animal suffering are minimized. I have argued, however, that this argument does not work for the following reasons. One is that the claimed humaneness of this sort of research is built on a rhetorical house of cards. Another is that the implied utility of animal research -- that is, its superior utility to alternative strategies of health-promotion that do not involve the experimental use of other animals -- is only presumed and has never been proved, and indeed is dubitable. A third reason is that any appeal to utility is bogus to begin with, since it would dictate the use of human experimental subjects instead of other animals, but we would not condone that. Fourth is that, when sufficiently knowledgeable and mindful of other animals and how they are treated in animal research, we do in fact value them sufficiently highly to resist their use in that way. Finally, even if there were convincing evidence of its optimal utility, animal research would not be justified because it violates a basic rule of morality against intentionally harming those who are both innocent and innocuous.

\section{Burden of Proof}

Strictly speaking that last argument was dialectical overkill. There was no need for me to offer a positive proof of the immorality of animal research if I had already refuted the researcher's best argument for its permissibility -- that is, given the presumption that 
the confinement, harming, and killing of animals does require some justification. I felt impelled to go the extra mile, though, for two reasons. My refutation relied on an empirical claim, namely, that the superior efficacy of animal research has not been convincingly demonstrated; but future research (on the efficacy of animal research), as well as the growing sophistication of animal research itself, could put the lie to that claim. So I wanted to do an end run around that possibility. Secondly, I wanted to understand the intuition that makes me care so much about this issue. For it's not just that animal research may be "suboptimal": It also generates outrage. I therefore wanted to discover and articulate the principle that explained this deep feeling within me.

Alas, my argument for the principle does not work. It is easy enough to think of a counterexample to it. I recall a striking one from the 1972 Swedish film The New Land (Nybyggarna), which is about the hardships of the pioneering Swedish settlers in Minnesota. In one scene the character played by Max von Sydow is caught in a blizzard with his little son on the way home from purchasing their pride-andjoy ox. The son is about to freeze to death. There is only one thing to do: Sydow takes an ax to the ox and carves out its steaming guts to provide a warm shelter for the little boy, thereby saving his life.

This powerful scene (I wonder how it was filmed!) has left such an impression after all these years. Interestingly I cannot recall having felt one iota of pity for the ox, not to mention moral outrage, this being from my pre-animal-consciousness days. I do remember how heart-wrenching it was to contemplate the loss of the human family's hard-won economic mainstay, namely, the ox. (Here we can truly speak of the sacrifice of an animal in the sense of being a sacrifice made by the family of its own valued property.) The sheer violence and novelty of the scene probably round out the explanation of its vividness in my memory. But in no way is there a moment's hesitation, now as then, regarding the aptness of the act on moral grounds. Indeed, the possibility of saving the boy in this way having occurred to one, it might seem just to condemn as immoral the 
failure to perform it. But the act is a clear violation of the principle I have put forward that one is not entitled to significantly harm a being who has not harmed or does not threaten harm to oneself or another who is harmless. For the ox had no role whatever in the harm being threatened to the boy; yet it seems meet to kill the ox to save the boy. ${ }^{15}$

How then stands the case of animal research? Is there a stalemate, since both the argument for and the argument against animal research have been refuted? I think not. For the burden of proof lay on the former. Why? Because of two considerations already adduced. First, animal research has a cost over and above any harm to the animals - what are called opportunity costs, which is to say, the missed opportunity of alternative uses of our healthcare dollars, which could prove more effective in advancing human health in the short and/or long term. But second, and more compelling, since the first is largely speculative: animal research involves cruelty to and killing of sentient beings who are innocent and innocuous. While this second fact by itself does not prove that animal research is morally wrong, it is surely sufficient to establish the need to prove that it is morally permissible if it is to be undertaken.

But the animal research proponent has failed to show that. Even if she is deeply moved by, say, the suffering of children in need of a medical cure, her intuition that animal research must be pursued full speed ahead hardly follows logically or morally if there is no proof that such research promises such a cure, not to mention, by the first consideration, might be diverting precious resources from finding it more efficaciously, or preventing the maladies in the first place. Therefore animal research, even in the absence of a definitive proof of its wrongness, is no more justified than killing your first-born to propitiate the gods, even though it may be impossible to prove that those bloodthirsty deities do not exist.

Let me put it in another way: The principle I have articulated is not a proof but a presumption, yet that is sufficient to demonstrate 
the impermissibility of animal research. The reason is that a presumption holds ceteris paribus, or "other things equal." In the example of the ox, other things were not "equal": by killing the ox, the little boy's life could probably be saved, which is enough to tip our considered intuitions in favor of the act. But in the case of most animal research, or perhaps all of animal research taken as an institution, there is insufficient evidence to overthrow the presumption that it is wrong to treat animals in these ways. ${ }^{16}$ Simply put: one needs a good reason to harm an animal, and the reason that experimenting on animals "might" help us find cures for terrible diseases, etc., is not good enough. This kind of "might" is as unlikely as the other to "make right." Too much suffering, not to mention expense, would be sanctioned for too little "payoff"; and indeed, as argued earlier, the goal of maximal human well-being could even be offset thereby.

Thus, while the presumption of the principle I have proposed does not provide absolute protection for animals, it may be the best that ethics has to offer. ${ }^{17}$ Yet, this could be sufficient for a vibrant antivivisection movement. A definite practical program is suggested by the theoretical state of affairs. First, since a strong case can be made that animal research is currently unjustified on the grounds of inefficacy or unproven maximal efficacy, as argued in the first part of this essay, those of us who advocate for animals will want to educate both the medical profession and the public (not to mention, ourselves!) about this. But since the medical community will in the meantime be striving to improve both the efficacy of animal research and the evidence of that efficacy, a further initiative by the animal protection community is likewise in order, namely, the active promotion of alternatives to animal research in the furtherance of human health.

What I am suggesting is analogous to the role veganism has come to play in the opposition to animal agriculture. Many animal advocates ${ }^{18}$ argue that the most effective strategy to end the 
exploitation of animals for human food is simply to get everybody to stop eating any animal products. ${ }^{19}$ But for this to become a mass movement, the public needs to be educated about edible alternatives. So it is not enough to harp on the atrocities of factory farming; we must also be promoting the joys and ease and benefits of a vegan diet. ${ }^{20}$ Just so, I am proposing that the vanguard of the antivivisection movement be, not only the drumbeat of exposés about the lives and deaths of laboratory animals, but also and perhaps especially the funding of research, training, and publicity about alternatives to the use of animals in laboratories. Furthermore, this would include not only laboratory alternatives, like computer models and cell cultures, ${ }^{21}$ but also, perhaps even primarily, alliances with healthy lifestyle campaigns. In sum: The end of animal exploitation is most likely to come about when human beings stop relying on animal products to satisfy their appetites and on doctors in order to be healthy. ${ }^{22}$

\section{Notes}

*. My subtitle takes its cue from the classic defense of animal research by Carl Cohen (Cohen 1986).

1. This way of putting the point is reminiscent of the humorous observation in The Hitchhiker's Guide to the Galaxy that, statistically speaking, given the teeming multitudes of beings in the galaxy, the Earth is uninhabited. This provided an excellent pretext for destroying the planet in order to build a hyperspace bypass.

2. "It is the position of the American Dietetic Association that appropriately planned vegetarian diets, including total vegetarian or vegan diets, are healthful, nutritionally adequate, and may provide health benefits in the prevention and treatment of certain diseases" (American Dietetic Association 2009).

3. An excellent discussion of contradiction as characterizing our whole use of other animals can be found in Satz 2009.

4. This is a constant theme of Dr. David L. Katz in his syndicated health columns; e.g., "From a preventionist's perspective, the lesser shame is our failure, to date, to wrest much new knowledge of practical value from our genome. By far, the greater shame ... is our 
failure to use the knowledge we already have [about] the overwhelming influence of lifestyle on health" (Katz 2010).

5. An interesting discussion of scientific skepticism about animal minds can be found in Allen and Bekoff 2007.

6. I credit Wayne Pacelle for bringing me to this realization.

7. A typical instance: Yale Prof. Marina Picciotto is quoted as saying, "I fundamentally believe that relieving human suffering or disease of children is worth the sacrifice of mouse lives" (Distler 2009).

8. Larry Carbone stresses this point throughout his book (Carbone 2004).

9. A critical assessment of this application can be found in Behnam Manesh 2010.

10. Not to mention that the standards are not even intended to be followed! From the previously cited Website: "We believe that an animal's welfare, whether on farm, in transit, at market or at a place of slaughter should be considered in terms of 'five freedoms'. These freedoms define ideal states rather than standards for acceptable welfare."

11. One caveat is the doctrine of double effect, according to which "sometimes it is permissible to bring about as a merely foreseen side effect a harmful event that it would be impermissible to bring about intentionally" (McIntyre 2009). Thus, in wartime it is not automatically considered wrong to drop a bomb on an enemy munitions factory even though it may inevitably injure or kill neighborhood residents who are innocent and innocuous. The point is: If one could take out the factory without harming the civilians, one would gladly do so.

12. Note that the doctrine of double effect does not save the day for animal research since, in many cases, one directly intends harm to the animals. How else, for example, to test an analgesic?

13. A review of the use of nonhuman primates in medical research, by the Medical Research Council and the Wellcome Trust (both in the $\mathrm{UK})$, can be found at http://www.mrc.ac.uk/Utilities/Documentrecord/index.htm? $\mathrm{d}=$ MRCo02558 (accessed May 29, 2010).

14. Not to mention that some lab animals have been or could be pets, e.g., dogs. Research animal use statistics compiled by the U.S. 
Department of Agriculture can be found here:

http://www.hsus.org/web-files/PDF/ARI/awreport2006-1.pdf

(accessed May 29, 2010). (Conspicuously absent, because not covered

by the Animal Welfare Act, are rats and mice.)

15. There is of course a far more obvious (apparent) counterexample to the principle, namely, our use of other animals as food. However, I discounted this from the outset as not capable of withstanding sustained moral scrutiny since, I cannot help but feel, most people, or at least most of those reading this article, would share my intuition that animal husbandry, or certainly factory farming, is unconscionable, were they but aware of (1) what really goes on or focusing on it, (2) our genuine nutritional needs, and (3) appetizing and economical alternatives. But in the ox case, I dare say, there is no "out."

16. Thus my conclusion accords with that of LaFollette and Shanks 1996:

... the moral onus always rests on anyone who wishes to perpetrate what is, all things being equal, a moral wrong. Since people on both sides of this debate, researchers included, acknowledge the moral status of non-human animals, then they must provide clear and demonstrable evidence that the value of the institution of research exceeds its moral costs. That they have not done. ... it is difficult to know how they could. (pp. 260-61)

17. The presumptive principle may still hold absolute sway with regard to human beings, as a prerogative we reserve for our own species. (This could be a way to understand the exquisite re-analysis of the trolley car cases in Thomson 2008.) Thus, my argument against animal research is compatible with speciesism. At this point I therefore wish to make explicit another presumption of my own, although not a normative one like the other but a meta-ethical one. I view morality as, at base, an expression of our desires. Indeed, I am prepared to dispense with moral language altogether as a way of cleaning house of any connotation of a universal and objective prescriptivity (cf. Garner 1994; and my own manuscript tentatively titled Bad Faith: A Philosophical Memoir on Atheism, Amorality, and Animals). Insofar as I concede speciesism, therefore, it is not as an ethical mandate but simply a nod to prevailing views.

18. See for example Francione 2009 and Hall 2010.

19. Cf. the refrain from the Vietnam War era: "Suppose they gave a war and nobody came?” 
20. See for example the Website, The Easy Vegan at http://www.theeasyvegan.com.

21. In the forefront of such work is the Alternatives Research \& Development Foundation, headquartered in Jenkintown, Pennsylvania, and on the Web at http://www.ardf-online.org/.

22. This essay owes a great deal to on-going dialogues with Robert Bass, Theresa Cunningham, David Katz, Mitchell Silver, Ian Smith, Peter Smith, and Wendell Wallach, steadfast assistance from Susan Kopp, Sue Leary, Carol Pollard, and David Smith, and the enduring inspiration of Gary Francione, Justin Goodman, Lee Hall, Melanie Stengel, and Persephone.

\section{References}

Allen, Colin and Marc Bekoff. 2007. Animal minds, cognitive ethology, and ethics. The J ournal of Ethics 11: 299-317.

American Dietetic Association. 2009. Vegetarian Diets. J ournal of the American Dietetic Association 109 (7): 1266-1282.

Bass, Robert. Forthcoming. Lives in the balance: Utilitarianism and animal research. In The ethics of animal research: In theory and practice, ed. Jeremy Garrett. MIT Press.

Behnam Manesh, Shima. 2010 (draft). The consideration of experimental animals' welfare in the frame of refinement.

Brown, Marilyn et al. 2006. Report of the working group on animal distress in the laboratory. Lab Animal 35 (8) (2006): 26-30.

Carbone, Larry. 2004. What animals want: Expertise and advocacy in laboratory animal welfare policy. New York, NY: Oxford University Press.

Cohen, Carl. 1986. The case for the use of animals in biomedical research. The New England J ournal of Medicine 314: 865-69.

Distler, Rebecca. 2009. The best laid plans of mice and men. Yale Daily News Magazine 36 (4): 11-16).

Farm Animal Welfare Council. 2009. Five freedoms. http://www.fawc.org.uk/freedoms.htm. Last modified April 16.

Francione, Gary L. 2007. The use of nonhuman animal in biomedical research: Necessity and justification. J ournal of Law, Medicine and Ethics 35(2):241-248. 
Garner, Richard. 1994. Beyond morality. Philadelphia, PA: Temple University Press.

Hall, Lee. 2010. On their own terms. Nectar Bat Press.

Katz, David. 2010. Genomic research argument overlooks something much more obvious. The New Haven Register, June 21, sec. A.

LaFollette, Hugh and Niall Shanks. 1996. Brute science: Dilemmas of animal experimentation. Routledge.

Linzey, Andrew. 2009. Why animals deserve special moral solicitude. AV Magazine (Fall) 8-10.

Petside Team. 2009. New poll reveals Americans often treat pets like humans. Associated Press, June 23. http://www.petside.com/the-sidewalk/ap_pets_poll.php.

McIntyre, Alison. 2009. Doctrine of Double Effect. The Stanford Encyclopedia of Philosophy, ed. Edward N. Zalta. http://plato.stanford.edu/archives/fall2009/entries/doubleeffect/. Last revised June 29.

Plous, Scott. 1999. Should the AWA cover rats, mice, and birds? The results of an IACUC survey. Lab Animal 28 (6): 38-40.

Pound, Pandora, Shah Ebrahim, Peter Sandercock, Michael B Bracken, and Ian Roberts on behalf of the Reviewing Animal Trials Systematically (RATS) Group. 2004. Where Is the Evidence that Animal Research Benefits Humans? BMJ 328 (February 28): 514-517.

Satz, Ani B. 2009. Animals as vulnerable subjects: Beyond interestconvergence, hierarchy, and property. Animal Law 16 (2).

Thomson, Judith Jarvis. 2008. Turning the Trolley. Philosophy \& Public Affairs 36 (4): 359-374.

Wolfson, David J. and Mariann Sullivan. 2004. Foxes in the hen house: Animals, agribusiness, a and the law: A modern American fable. In Animal rights: Current debates and new directions, ed. C. R. Sunstein and M. C. Nussbaum, 205-233. New York, NY: Oxford University Press.

Zimmermann, Manfred on behalf of the Committee for Research and Ethical Issues of the International Association for the Study of Pain (IASP). 1983. Ethical Guidelines for Investigations of Experimental Pain in Conscious Animals. Pain 16: 109-10. 